\title{
Prevalência de Gardnerella vaginalis em mulheres atendidas em uma Unidade Básica de Saúde no município de Macapá- AP
}

\author{
Prevalence of Gardnerella vaginalis in women treated at a Basic Health Unit in the city of Macapá - AP
}

\author{
Jean Railan Santana ${ }^{1} \bullet$, Claude Porcy ${ }^{\ominus}$, Flavio Henrique Ferreira Barbosa ${ }^{2} \bullet$, Rubens Alex de \\ Oliveira Menezes ${ }^{3^{*}} \bullet$
}

${ }^{1}$ Faculdade Estácio de Macapá, Macapá, Amapá, Brasil. ²Departamento de Morfologia, Universidade Federal de Sergipe, São Cristóvão, Sergipe, Brasil. ${ }^{3}$ Departamento de Ciências Biológicas e da Saúde, Universidade Federal do Amapá, Macapá, Amapá, Brasil. *Autor para correspondência. E-mail: ra-menezes@hotmail.com/rubens.alex@unifap.br

\begin{abstract}
Resumo: Introdução: A Gardnerella vaginalis é uma bactéria da microbiota vaginal das mulheres sexualmente ativas, contudo em situações de perturbação como stress, infecções, gravidez e uso de DIU podem apresentar multiplicação exagerada gerando uma superpopulação resultando em um quadro chamado de vaginose bacteriana. Objetivo: Abordar os principais aspectos epidemiológicos e clínicos da vaginose bacteriana ocasionada por Gardnarella vaginalis em mulheres atendidas em uma Unidade Básica de Saúde no município de Macapá-AP no período de 2018. Material e métodos: Trata-se de um estudo descritivo de abordagem quantitativa no qual foram utilizados dados secundários obtidos a partir dos laudos de exames de secreção vaginal de rotina de janeiro de 2018 a dezembro de 2018, no Laboratório Municipal da Unidade Básica de Saúde de Macapá-AP. As informações coletadas foram transferidas para uma planilha no aplicativo Microsoft Excel 2016 onde foram realizados os cálculos e a tabulação dos resultados. Resultados e discussão: Foram incluídas pacientes com ou sem sintomas, de faixa etária de 18 a 56 anos, observou-se a ocorrência de Gardnerella vaginalis em 133 mulheres de 524 exames, no qual pode-se concluir que a faixa etária onde houve maior índice de casos foi entre 18 aos 30 anos. Considerações finais: Esse trabalho tem como finalidade discutir sobre a bactéria Gardnerella vaginalis que se mostra como uma doença prevalente entre as mulheres. Desta forma, a G. vaginalis é um dos principais microrganismos causadores da vaginose bacteriana que usam como porta, mulheres suscetíveis a essa contaminação.
\end{abstract}

Palavras-chave: vaginose bacteriana, Gardnerella vaginalis, "Clue cells”.

\begin{abstract}
Introduction: Gardnerella vaginalis is a bacterium in the vaginal microbiota of sexually active women, however, in disturbing situations such as stress, infections, pregnancy and IUD use, it can show an excessive multiplication, generating an overpopulation resulting in a condition called bacterial vaginosis. Objective: To address the main epidemiological and clinical aspects of bacterial vaginosis caused by Gardnarella vaginalis in women treated at a Basic Health Unit in the municipality of Macapá-AP in the period of 2018. Material and methods: This is a descriptive study with a quantitative approach in which secondary data obtained from the reports of routine vaginal secretion exams from January 2018 to December 2018 were used, at the Municipal Laboratory of the Basic Health Unit of Macapá-AP. The collected information was transferred to a spreadsheet in the Microsoft Excel 2016, where the results were calculated and tabulated. Results and discussion: Patients with or without symptoms, aged 18 to 56 years, were included, Gardnerella vaginalis was observed in 133 women from 524 exams, in which it can be concluded that the age group where there was a higher index of cases was between 18 to 30 years old. Final considerations: This study aims to discuss the bacteria Gardnerella vaginalis, which is shown to be a prevalent disease among women. Thus, G. vaginalis is one of the main microorganisms that cause bacterial vaginosis that use as a door, women susceptible to this contamination.
\end{abstract}

Keywords: bacterial vaginosis, Gardnerella vaginalis, "Clue cells".

\section{Introdução}

Dentre as infecções humanas, as das vias urinárias estão entre as mais comuns, ocupando lugar de destaque no cenário das infecções, ficando apenas atraz das infecções respiratórias. As infeções urinárias resultam em milhões de consultas médicas e de admissões em hospitais por ano. A frequência exata das infecções do trato urinário (ITUs) nã é totalmente conhecida, entretanto, de acordo com evidências de consultórios médicos e prontuários hospitalares, é estimada a prevalência de cistite e de pielonefrite por ano nos Estados Unidos da América (Silveira et al., 2010). 
O canal vaginal apresenta várias bactérias da microbiota que vivem em harmonia com o Lactobacillus $s p$, espécie bacteriana predominante no meio vaginal e responsável pela determinação do pH ácido que impede o crescimento de demais espécies bacterianas lesivas à mucosa vaginal (Marrazo, 2003). O desequilíbrio da harmonia vaginal é caracterizado pela substituição da microbiota (lactobacilar normal) por concentrações de outras bactérias patogênicas ao trato vaginal, principalmente anaeróbias, que desencadeia um fenômeno chamado de vaginose bacteriana (VB) (Consolaro \& Maria-Engler, 2012).

Adicionalmente, a vaginose bacteriana é uma das causas mais comuns de infecção vaginal em mulheres sexualmente ativas e em idades férteis, indicando a possibilidade da interferência hormonal presente e envolvidas na sua patogênese (Simões et al., 2006). As inflamações do trato vaginal está entre as principais causas de consulta ginecológica. Ademais, a Vaginose Bacteriana (VB), candidíase e tricomoníase são responsáveis por vários casos de vaginites (Hasenack et al., 2008).

Os casos de vaginites, geralmente ocorre pelo contato íntimo ou relação sexual, a vaginose é a causa mais comum de corrimento genital. Essa infecção desencadeia um desequilíbrio da flora vaginal fazendo com que a concentração de determinadas bactérias aumente. Atualmente, a Vaginose Baceteriana é considerada uma proliferação maciça de uma flora mista, que inclui a Gardnella Vaginallis. Ademais, biologicamente as mulheres mais suscetíveis às doenças sexualmente transmissíveis (DSTs) e a maioria é assintomática (Tanaka et al., 2007).

A microbiota vaginal é constituído por microrganismos com predominância de Lactobacillus que produz ácido lático, permitindo manter um $\mathrm{pH}$ ácido criando um ambiente hostil para a proliferação de agentes patogénicos oportunistas. Entretanto, o seu equilíbrio é frágil e mudanças na sua composição causam infeções (Dall'alba \& Jaskulski, 2014). Ademais, os lactobacilos de Döderlein, tem sido descrito como ecossistema complexo e em equilíbrio dinâmico, sua composição varia muito de uma pessoa para outra, sendo a microbiota vaginal fator chave na proteção do hospedeiro contra vários agentes patogénicos bacterianos, fúngicos ou virais (Tanaka et al., 2007).

No estado do Amapá há uma carência de estudos direcionados especificamente ao perfil epidemiológico da Gardnerella vaginalis. Outro ponto a ser considerado se refere às seqüelas da doença não tratada que são: aumento do risco de adquirir DSTs, infertilidade, endometrite, trabalho de parto prematuro, baixo peso do recém-nascido entre outras afecções. Diante de tais discussões, verificou-se a necessidade de um conhecimento sobre a prevalenci dessa doença na população do estado, o que poderá servir de subsídios para novos estudos sobre este tema e fomentar sua discussão. O objetivo do presente estudo é abordar os principais aspectos epidemiológicos e clínicos da vaginose bacteriana ocasionada por Gardnarella vaginalis em mulheres atendidas em uma Unidade de Saúde no município de Macapá-AP no período de 2018.

\section{Materiais e métodos}

Trata-se de um estudo descritivo de abordagem quantitativa no qual foram utilizados dados secundários obtidos a partir dos laudos de exames de secreção vaginal de rotina de janeiro de 2018 a dezembro de 2018, no Laboratório Municipal de uma Unidade Básica de Saúde de Macapá-AP. As informações obtidas foram armazenadas em uma planilha no aplicativo Microsoft Excel 2016, obtidos da base de dados do sistema de informação da rede municipal UNILAB, após a autorização da direção da Unidade, sendo incluídas pacientes da faixa etária de 18 a 56 anos.

A pesquisa seguiu a Resolução ${ }^{\circ} 466$ de 2012 da Comissão Nacional de Ética em Pesquisa do Ministério da Saúde, na qual sistematiza as normas éticas regulamentadoras de pesquisas envolvendo seres humanos, sendo as atividades desenvolvidas na pesquisa fundamentadas pela Resolução do Conselho Nacional de Saúde (Brasil, 2012).

\section{Resultados e discussão}

No período de janeiro 2018 a dezembro de 2018 foram realizados 524 exames de bacterioscopia, onde verificou-se a ocorrência de Gardnerella vaginalis em 133 (25,3\%) mulheres. Observou-se que em mulheres com faixa etária de 18 a 30 anos, obtiveram maior índice de Gardnerella vaginalis (Figura 1) com um total de 83 $(27,4 \%)$ exames positivos. Na faixa etária estabelecida de 31 a 43 anos, foram 35 (23,8\%) exames positivos, bem como na faixa etária de 44 a 66 anos, foram 15 (18,5\%) resultados positivos, que essa faixa etária estabelecida evidenciando a menor prevalência da bactéria. 


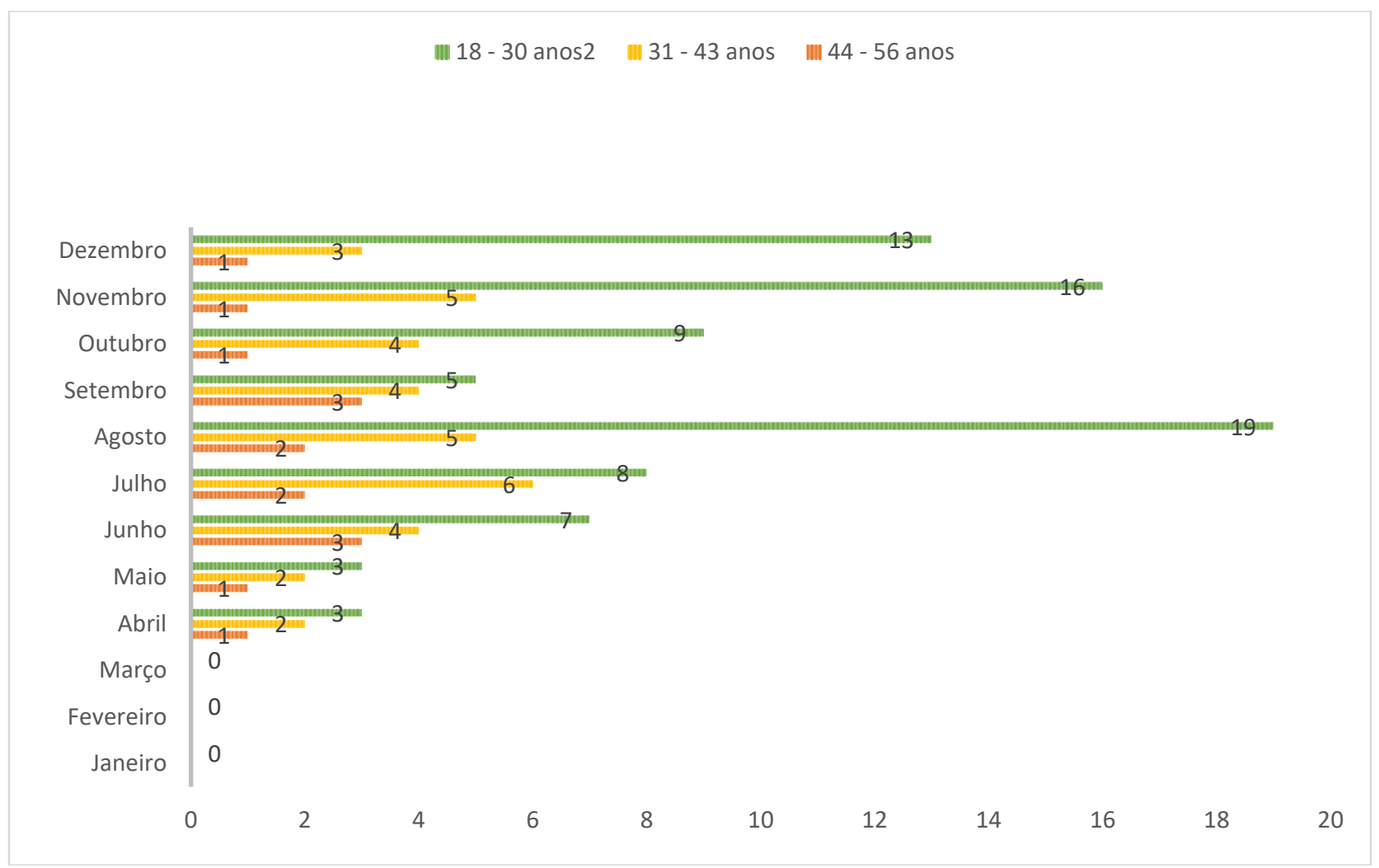

Figura 1. Prevalência de Gardnerella vaginalis de janeiro a dezembro de 2018

De acordo com o estudo realizado, considerando os casos positivos (25,3\%) na faixa etária de 18 a 30 anos, ocorreram as maiores prevalências de infecções por Gardnerela Vaginalis, Segundo Oliveira e Soares (2007), 35-50\% das mulheres jovens e sexualmente ativas, as inflamações e/ou infecções vaginais estão entre as principais causas de consultas ginecológicas. Os casos de Vaginose Bacteriana ocorrem em mulheres sexualmente ativas com idade compreendida entre 15 e 44 anos, especialmente após contato com um novo parceiro (Bradshaw et al., 2006). A ocorrência de desequilíbrio e das alterações na microbiota vaginal durante a fase reprodutiva pode ser explicada pela atividade sexual, condições de saúde e higiene dos parceiros sexuais (Vasconcelos \& Martins, 2005).

Adicionalmente, Ribeiro et al. (2007) descrevem que a infecção por Gardnerella vaginalis, frequentemente tem sido associada a fatores socioculturais como idade, falta de educação sexual adequada, grau de escolaridade e ocupação, que reflem em atitudes associadas a maus hábitos de higiene, como grande número de parceiros, início precoce da vida sexual, principalmente, associado à falta de uso de preservativos. Santos et al. (2006) em estudo semelhante em pacientes ambulatoriais de um laboratório em Porto Alegre-RS, encontraram uma baixa prevalência (2,06\%) na associação entre Gardnerella vaginalis e Candida sp.

Neste trabalho, foi evidenciado a prevalência da VB por Gardnerella vaginalis diagnosticada entre mulheres na faixa etária de 44-56 anos, equivalente a 18,5\% um pouco abaixo em relação as outras faixas etárias. Entretanto, Hasenak et al. (2006), contrariando diversos estudos, explicaram que, a constatação da menor prevalência dessa patologia em mulheres acima de 40 anos, aparentemente, um paradoxo, visto que a fase da menopausa é acompanhada por um decréscimo na colonização vaginal por lactobacilos e um aumento do pH.

Cardoso et al. (2000) informa que quando a mulher inicia o período da menopausa, ocorre diminuição do estrogênio, o epitélio vaginal torna-se mais delgado ocasionando diminuição ou até ausência de glicogênio. Acredita-se que a redução do glicogênio seja responsável, pelo menos parcialmente, pela diminuição de lactobacilos e elevação do $\mathrm{pH}$ evidenciados na vagina dessas mulheres, predispondo-as, devido às mudanças do ambiente, que a vagina seja colonizada por bactérias patogênicas. Neste estudo, foram coletados dados totais a cada mês do ano de 2018, a qual podemos observar (Figura 2) as variações de coletas para a realização dos exames de secreção vaginal no ano. 


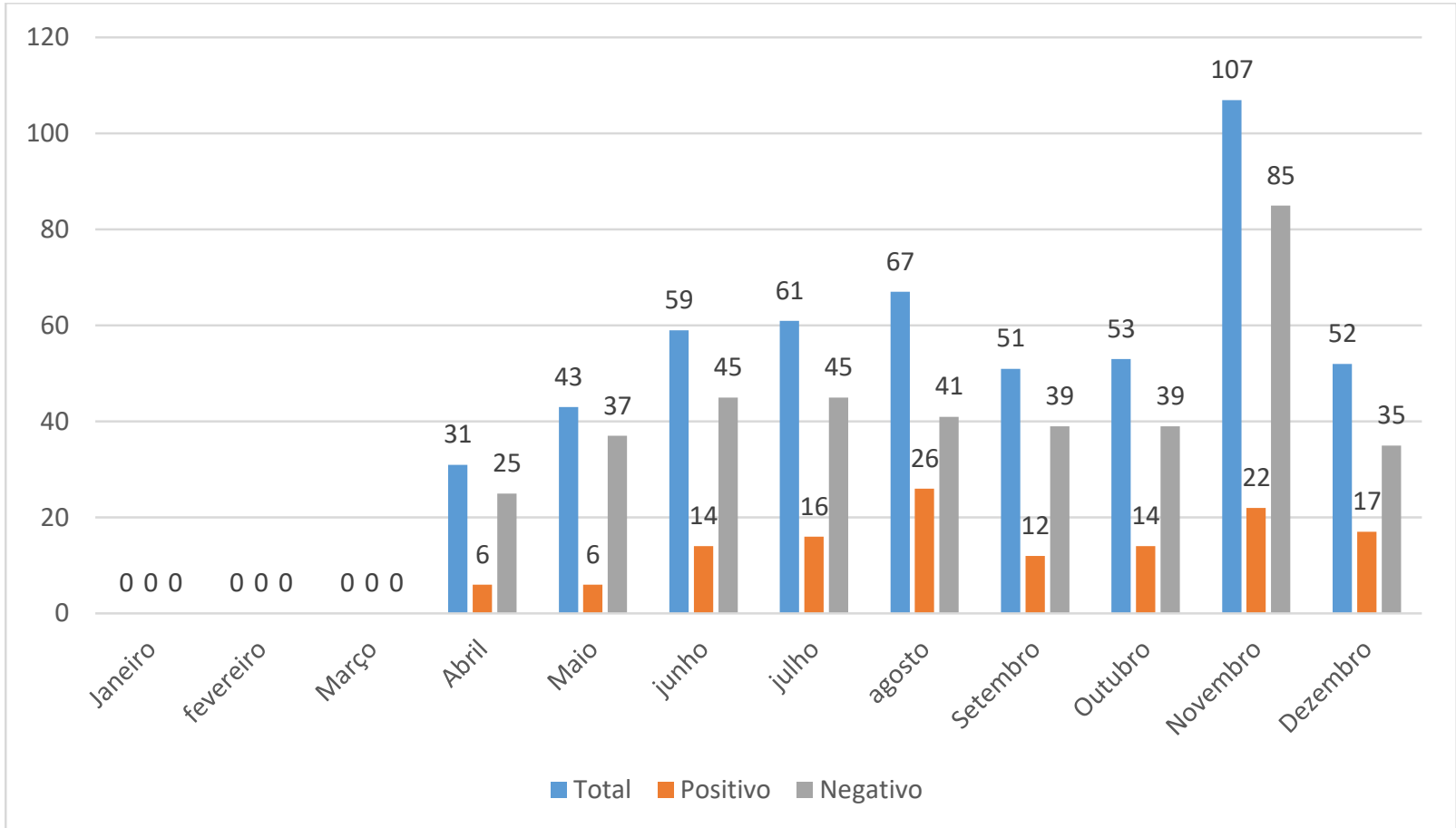

Figura 2. Coletas realizadas para a investigação de Gardnerella vaginalis.

Ademais, grande parte das mulheres apresentam episódios recorrentes da doença, mesmo com a realização do tratamento de forma adequada. Sendo assim, faz-se necessária a realização de estudos nesta área, visto que os hábitos de vida estão diretamente relacionados com o surgimento dessa enfermidade. Pôde-se observar números bastante consideráveis de casos positivos no ano de 2018, no qual houveram meses que apresentaram um pico mais elevado do que o normal, o que pode ser entendido como ações preventivas que foram realizadas na Unidade Básica para prevenções dessa e de outras bactérias que foram muito bem atendidas e diagnosticadas.

Para elucidar o motivo de uma elevada prevalência de vaginose, os fatores de risco correlacionados a esta doença foram investigados. Nesse estudo, tabagismo, uso de DIU e histórico prévio de vaginose foram associados. O hábito de fumar também mostrou-se relacionado com o surgimento de vaginose no estudo realizado por Brotman et al. (2014), evidenciando a redução da microbiota lactobacilar protetora em mulheres fumantes diminuída quando comparada a de não fumantes.

Ademais, alguns autores mostraram que o cigarro possui efeito antiestrogênico, além de permitir o acúmulo de aminas no epitélio vaginal, predispondo a mulher a desenvolver vaginose (Hellberg et al., 1988; Westhoff et al., 1996). Os resultados do presente estudo foram provenientes de serviços de saúde pública, os quais tem como predomínio indivíduos desfavorecidos economicamente, sem acesso a planos de saúde. Os dados encontrados destacam para um problema de saúde pública, uma vez que as infecções vaginais estão inclusas entre as doenças sexualmente transmissíveis. Adicionalmente, o conhecimento dos dados reforça a necessidade da adoção precoce de medidas para à detecção, tratamento e acompanhamento de casos.

\section{Considerações finais}

A pesquisa demostra que mulheres sexualmente ativa e com idade reprodutiva estão sugeitas a apresentar infecções ou corrimentos, constatando a frequência de G. Vaginalis. Desta forma, a G. Vaginalis é um dos principais microrganismos causadores da vaginose bacteriana, destacando-se na infecção do trato genital feminino. Esta bactéria está relacionada com o desequilíbrio dos Lactobacillus spp, gerando várias doenças ginecológicas, sendo que o uso de probióticos tópico ou oral promove um equilíbrio desta microbiota, reduzindo os sintomas no caso de infeção vaginal, bem como a probabilidade de recorrência. 


\section{Referências}

Bradshaw, C. S., Morton, A. N., Hocking, J., Garland, S. M., Morris, M. B., Lorna M., Moss, L. M., Horvath, L. B., Kuzevska, I., \& Fairley, C. K. 2006. High recurrence rates of bacterial vaginosis over the course of 12 months after oral metronidazole therapy and factors associated with recurrence. Journal of Infectious Diseases. 43 (11), 1478-1486.

Brasil. 2012. Resolução $n^{\circ} 466$ de 12 de Dezembro de 2012. Define as normas éticas regulamentadoras de pesquisas envolvendo heres humanos. Disponível em: <https://conselho.saude.gov.br/resolucoes/2012/Reso466.pdf>. Acesso em: 18 jul. 2020.

Brotman, R. M., He, X., Gajer, P., Fadrosh, D., Sharma, E., Mongodin, E. F., Ravel, J., ... Rath, J. M. 2014. Association between cigarette smokingand the vaginal microbiota: a pilot study. BMC Infect Dis, 14, 471.

Cardoso, M. S. R., Ramos, E. S. N., Castro, A. D. P., Ramos, D. K. N., Silva, D. G. K. C., \& Cavalcanti Junior, G. B. 2000. Prevalência de vaginites específicas e inespecíficas em mulheres na pós-menopausa. Revista Brasileira de Análises Clínicas. 32 (4), 275-277.

Consolaro, M. E. L, \& Maria-Engler, S. S. 2012. Citologia Clínica Cérvico-vaginal: Texto e Atlas. São Paulo, SP: Roca.

Dall'alba, M. P., \& Jaskulski, M. R. 2014. Prevalência de vaginoses bacterianas causadas por Gardnerella vaginalis, em um laboratório de análises clínicas na cidade de Santo Expedito do Sul, RS. Revista Perspectiva, 38, 91-99.

Hasenack, B. S., Miquelão, A. K. M.B., Marquez, A. S., Pinheiro, E. H. T., \& Urnau, A. P. 2008. Estudo Comparativo dos diagnósticos de vaginose bacteriana pelas técnicas de Papanicolaou e Gram. Revista Brasileira de Analises Clinicas, 40 (2), 159-162.

Hellberg, D., Nilsson, S., Haley, N. J., Hoffman, D., \& Wynder, E. 1988. Smoking and cervical intraepithelial neoplasia: nicotine and cotinine in serum and cervical mucus in smokers and nonsmokers. American Journal of Obstetrics and Gynecology, 158(4), 910-913.

Marrazzo, J. M. 2003. Bacterial vaginosis. Current Treatment Options in Infectious Diseaes, 5, 63-68.

Oliveira, E. H., \& Soares, L. F. 2007. Prevalência de vaginites infecciosas através da citologia clínica: Um estudo no Laboratório Central de Saúde Pública do Piauí, Revista Brasileira de Análises Clínicas, 39(1), 33-35.

Ribeiro, A. A., Oliveira, D. F., Sampaio, M. C. N., Carneiro, M. A. S., Tavares, S. B. N., Souza, N. L. A., ... Santos, S.H.R. 2007. Agentes microbiológicos em exames citopatólogicos: estudo de prevalência. Revista Brasileira de Análises Clínicas, 39(3), 179-181.

Santos, R. C. V., Pulcinelli, R. S. R., Vizzotto, B. S., \& Aquino, A. R. C. 2006. Prevalência de Vaginoses Bacterianas em pacientes ambulatoriais no Hospital Divina Providência, Porto Alegre, RS. NewsLab, 75, 160-164.

Silveira, A. C. O., Souza, H. A. P. H. M., \& Albini, C. A. 2010. A Gardnerella vaginalis e as infecções do trato urinário. J. Bras. Patol. Med. Lab., 46 (4), 295-300.

Simões, J., Ocaña, V., Aroutcheva, A., Camargo, R., Nadermacías, M. E., \& Faro, S. 2006. Bacteriocinas produzidas por lactobacilos e sua importância para o trato genital feminino. Feminina, 10(29), 705-10.

Tanaka, V. A., Fagundes, L. J., Catapan, A., Gotlieb, S. L. D., Belda J. R. W., Arnone, M., Soreano, R. \& Moraes, F. R. B. 2007. Perfil epidemiológico de mulheres com vaginose bacteriana, atendidas em um ambulatório de doenças sexualmente transmissíveis, em São Paulo, SP. Anais Brasileiros de Dermatologia, 82(1), 41-46.

Vasconcelos, S. A. M., \& Martins, L. A. 2005. Correlação entre as alterações microbiológicas e o conhecimento das alterações presentes no laudo do exame colpocitológico pelas mulheres do município de Douradina em 2004. Arquivos de Ciências da Saúde Unipar, 9(3), 167-173.

Westhoff, C., Gentile, G., Lee, J., Zacur, H., \& Helbig, D. 1996. Predictors of ovarian steroid secretion in reproductive-age women. American Journal of Epidemiology, 144(4), 381- 388.

\section{Minicurrículo}

Jean Railan Santana. Bacharelado em Biomedicina da Faculdade Estácio de Macapá. Macapá, Amapá, Brasil. 
Claude Porcy. Graduação em Biomedicina, Especialização em Análises Clínicas; e em Tecnologia de Software, mestrado em Biologia Parasitária (área de concentração em Biologia da Interação Patógeno-Hospedeiro). Atualmente é Professor de Microbiologia e Bacteriologia da Faculdade Estácio de Macapá e Biomédico do Governo do Estado do Amapá. Tem experiência em Análises Clínicas com ênfase nas áreas da Hematologia e Microbiologia médica.

Flavio Henrique Ferreira Barbosa. Professor Adjunto II (Dedicação Exclusiva) da Universidade Federal de Sergipe - UFS, vinculado ao Departamento de Morfologia - DMO na Área de Conhecimento: Microbiologia e Imunologia. Possui Graduação em Ciências Biológicas pelo Centro Universitário Metodista Izabela Hendrix/MG (2003), Especialista em Saúde Pública (em andamento) pela Fundação Estadual de Saúde de Sergipe - FUNESA/Universidade Federal de Sergipe - UFS (2020), Especialista em Gestão e Manejo Ambiental pela Universidade Federal de Lavras - UFLA/MG (2008), Especialista em Didática e Metodologia do Ensino Superior pela Anhanguera Educacional/DF (2009), Mestrado em Microbiologia pela Universidade Federal de Minas Gerais - UFMG (2006) e Doutorado em Microbiologia pela Universidade Federal de Minas Gerais - UFMG (2010). Realizou estágio Pós-Doutoral na Universidade Rovira i Virgili, Espanha (2018-2019) na área de Fermentação e Tecnologia Cervejeira (Cerveja Artesanal). Formou-se Mestre Cervejeiro Artesanal e Sommelier (2019). Tem como linhas de pesquisa estudos de microbiologia das fermentações; leveduras de cervejaria e tecnologia cervejeira. Já atuou em pesquisas nas linhas de ecologia e fisiologia microbiana das superfícies e mucosas do hospedeiro humano e outros animais; estudo e desenvolvimento de probióticos e prebióticos; biotecnologia e biodiversidade de microrganismos; e pesquisa de substâncias antagonistas e antimicrobianas produzidas por microrganismos e plantas. É líder do Grupo de Pesquisa: Microbiologia das Fermentações e Tecnologia Cervejeira (www.cervejaufs.com.br). É integrante da equipe de pesquisadores do Grupo de Pesquisa: Microbiologia e Imunologia (UFS) e Microbiologia Aplicada (UFS).

Rubens Alex de Oliveira Menezes. Graduação em Enfermagem (Bacharelado e Licenciatura) pela Universidade Federal do Amapá (2009). Pós-Graduação em Microbiologia Nível de Especialização pela Universidade de Fortaleza, Pós-Graduação em Docência do Ensino Superior pela Faculdade de Tecnologia do Amapá - META, Pós-graduação em Gestão em saúde pública pela Faculdade de Macapá - FAMA, PósGraduação Nível de Mestrado em Ciências da Saúde Área de Concentração: Epidemiologia e Saúde Pública pela Universidade Federal do Amapá (2013). Pós-graduação Nível de Doutorado em Biologia de Agentes Infecciosos e Parasitários (PPG BAIP) pela Universidade Federal do Pará. Atualmente é docente do curso de enfermagem da Universidade Federal do Amapá (UNIFAP), Adjunto I, atuando na linha de pesquisa direcionada as doenças emergentes, reemergentes e negligenciadas, desenvolvendo estudos com enfoque especial em: Saúde pública e epidemiologia e controle de doenças transmissíveis, não transmissíveis, infecciosas e parasitárias de interesse médico-sanitário.

Como citar: Santana, J.R., Porcy, C., Barbosa, F.H.F., \& Menezes, R.A.O. 2021. Prevalência de Gardnerella vaginalis em mulheres atendidas em uma Unidade Básica de Saúde no município de Macapá- AP. Pubsaúde, 5, a103. DOI: https://dx.doi.org/10.31533/pubsaude5.a103

Recebido: 20 nov. 2020.

Revisado e aceito: $1 \mathrm{dez} .2020$.

Conflito de interesse: os autores declaram, em relação aos produtos e companhias descritos nesse artigo, não ter interesses associativos, comerciais, de propriedade ou financeiros que representem conflito de interesse.

Licenciamento: Este artigo é publicado na modalidade Acesso Aberto sob a licença Creative Commons Atribuição 4.0 (CC-BY 4.0). 